\title{
Lessons to be learned: best and worst results from a 7 years old clinical database of scoliosis patients
}

\author{
S Negrini ${ }^{*}$ S Donzelli, F Zaina \\ From 8th International Conference on Conservative Management of Spinal Deformities and SOSORT 2011 \\ Annual Meeting \\ Barcelona, Spain. 19-21 May 2011
}

\section{Background and purpose}

To verify which patients can reach the best and worst results during conservative treatment, since it is not yet known from previous researches $[1,2]$.

\section{Material and methods}

All scoliosis patients with more than 2 visits included in a prospective clinical database started in September 2003 were reviewed on August 31st 2010. A cut-off of 20 degrees (improvement or worsening) from the first observation was used to select patients. Patients were analysed for diagnosis, morphology, Cobb angle at start, curve improved/worsened, treatment, gender, Body Mass Index, clinical parameters.

\section{Results}

Out of 1886 consecutive patients (TP), 62 (3.3\%) changed $20^{\circ}$ or more: $26(1.4 \%)$ improved (range $\left.20-34^{\circ}\right)$ (IP), $36(1.9 \%)$ progressed $\left(20-60^{\circ}\right)(\mathrm{PP})$.

Females prevailed in IP and low BMI in PP. In PP prevailed juveniles ( $35 \%$ vs $15 \%-23.8 \%$ in IP-TP); conversely, secondary scoliosis prevailed in both PP and IP (25\%-15\% respectively vs $1.9 \%$ in $\mathrm{TP}$ ). In IP there were only patients who started over $30^{\circ}$ Cobb (100\%), while in PP $47 \%$ started between 10 and $19^{\circ}$; corresponding percentages in TP were $33.9 \%$ and $28.5 \%$ respectively. Diagnosis of thoracolumbar single curve was the most common in IP ( $46 \%$ vs $22.1 \%$ in TP), while double in PP (67\% vs $49.8 \%$ in TP). Curves improved were thoracolumbar (IP: 58\%), worsened thoracic (PP: 78\%). Only patients who had a good or optimum treatment improved, but this was true also in $56 \%$ of progressed.

ISICO, Milan, Italy

\section{Conclusions}

Since these results are not similar to what would be expected according to the known natural history, conservative treatment appears able to change it.

Published: 27 January 2012

\section{References}

1. Negrini S, Atanasio S, Fusco C, Zaina F: Effectiveness of complete conservative treatment for adolescent idiopathic scoliosis (bracing and exercises) based on SOSORT management criteria: results according to the SRS criteria for bracing studies- SOSORT Award 2009 Winner. Scoliosis 2009, 4:19.

2. Negrini S, Grivas TB, Kotwicki T, Rigo M, Zaina F: Guidelines on "Standard of management of idiopathic scoliosis with corrective braces in everyday clinics and in clinical research": SOSORT Consensus 2008. Scoliosis 2009, 4(1):2.

doi:10.1186/1748-7161-7-S1-O28

Cite this article as: Negrini et al:: Lessons to be learned: best and worst results from a 7 years old clinical database of scoliosis patients. Scoliosis 2012 7(Suppl 1):O28.
Submit your next manuscript to BioMed Central and take full advantage of:

- Convenient online submission

- Thorough peer review

- No space constraints or color figure charges

- Immediate publication on acceptance

- Inclusion in PubMed, CAS, Scopus and Google Scholar

- Research which is freely available for redistribution

\section{Biomed Central}

(C) 2012 Negrini et al; licensee BioMed Central Ltd. This is an open access article distributed under the terms of the Creative Commons Attribution License (http://creativecommons.org/licenses/by/2.0), which permits unrestricted use, distribution, and reproduction in any medium, provided the original work is properly cited. 